\title{
APLIKASI DIAGNOSA PENYAKIT KETURUNAN PADA MANUSIA DENGAN METODE BACKWARD CHAINING BERBASIS WEB
}

\author{
Juni Anna Fransisca, Oktavia, Kristy Santi Siregar, Okta Jaya Harmaja, Siti Aisyah* \\ Program Studi Sistem Informasi Fakultas Tekonologi dan Ilmu Komputer Universitas Prima Indonesia \\ E-mail : *sitiaisyah@unprimdn.ac.id
}

\begin{abstract}
ABSTRAK - Penyakit keturunan merupakan penyakit yang dikarenakan tidak seimbangnya kondisi tubuh terhadap lingkungan sehingga menjadi penyakit yang dapat dirasakan secara langsung maupun tidak langsung pada tubuh manusia, dan dapat diwariskan pada keturunan, terdapat berbagai rangsangan atau zat dari luar tubuh misalnya terhadap makanan, debu, obat - obatan dan sebagainya. dimana kondisi tersebut biasanya ringan ataupun berat yang menyebabkan kematian. Hasil penelitian dihitung menggunakan Certainty Faktor dengan interprestasi, Jika -1.0 maka pasti tidak, -0.8 maka hampir tidak pasti, $-0,6$ kemungkinan besar tidak, -0.4 mungkin tidak, -0.2-0.2 tidak yakin, 0.4 mungkin, 0.6 kemungkinan besar, 0.8 hampir pasti, 1.0 pasti.

Sangat diharapkan untuk setiap orang terutama yang merasakan gejala - gejala penyakit agar memeriksakan diri ke rumah sakit, guna mencegah atau mengantisipasi semakin parahnya gejala atau penyakit yang ada didalam tubuh. Tujuan penelitian adalah mengungkapkan gejala - gejala penyakit keturunan pada manusia.
\end{abstract}

Katakunci : manusia, factor penyakit, penyakit keturunan

\section{PENDAHULUAN}

Salah satu hal terpenting bagi masyarakat saat ini adalah secanggih apa teknologi yang berkembang saat ini. Teknologi yang semakin maju dapat memudahkan masyarakat dalam menjalankan aktifitas, serta menjalankan pekerjaannya dengan lebih mudah.

Kesehatan merupakan salah satu hal terpenting bagi manusia, karena dengan sehat manusia bisa menjalankan aktifitasnya sehari-hari dengan baik. Kebanyakan Masyarakat pada zaman sekarang telah menyadari bahwa hampir semua yang dikonsumsi mengandung zat berbahaya, oleh karenanya manusia mulai memperhatikan kesehatan nya dengan melakukan serangkaian tes pada tubuhnya sebelum mengidap suatu penyakit. Akan tetapi jika melakukan tes di rumah sakit harus membayar administrasi dan melakukan antrian, hal itu menjadi kendala bagi masyarakat yang kurang mampu, karena tidak semua masyarakat bisa membayar administrasi untuk tes yang ada. Seorang pakar kesehatan yang memiliki keahlian untuk mendiagnosa penyakit yang dikuasai, maka untuk menyelesaikan permasalahan penyakit dalam dunia kesehatan yang dialami, seluruh kalangan terhalangi oleh banyaknya jumlah kalangan dan jarak tempuh yang memakan waktu yang cukup banyak[5].

Penyakit keturunan adalah penyakit yang diwariskan oleh salah satu atau kedua orangtua, namun ada orangtua yang hanya sebagai carrier, penyakit akan menjadi aktif apabila anak yang menerima gen penyakit tersebut tidak bisa menjaga pola hidupnya. Salah satu cara untuk mencegah penyakit-penyakit tersebut menurun ke generasi berikutnya adalah dengan melakukan pemeriksaan lengkap sebelum menikah. Karena dari pemeriksaan ini akan diketahui apakah keduanya memiliki gen penyakit yang diturunkan ke anaknya kelak atau tidak sehingga bisa lebih siap menghadapinya
Berdasarkan uraian diatas, penulis tertarik untuk mengembangkan suatu aplikasi diagnosa dengan metode backward chaining berbasis web. Aplikasi tersebut menjadi suatu karya tugas akhir(skripsi) dengan judul "Aplikasi Diagnosa Penyakit Keturunan Pada Manusia Dengan Metode Backward Chaining Berbasis Web". Penulis berharap dengan adanya aplikasi ini dapat membantu masyarakat dalam mengurangi angka penyakit keturunan.

\section{METODE PENELITIAN}

Adapun beberapa tahapan metode penelitian tersebut dijelaskan melalui gambar dibawah ini, yaitu :

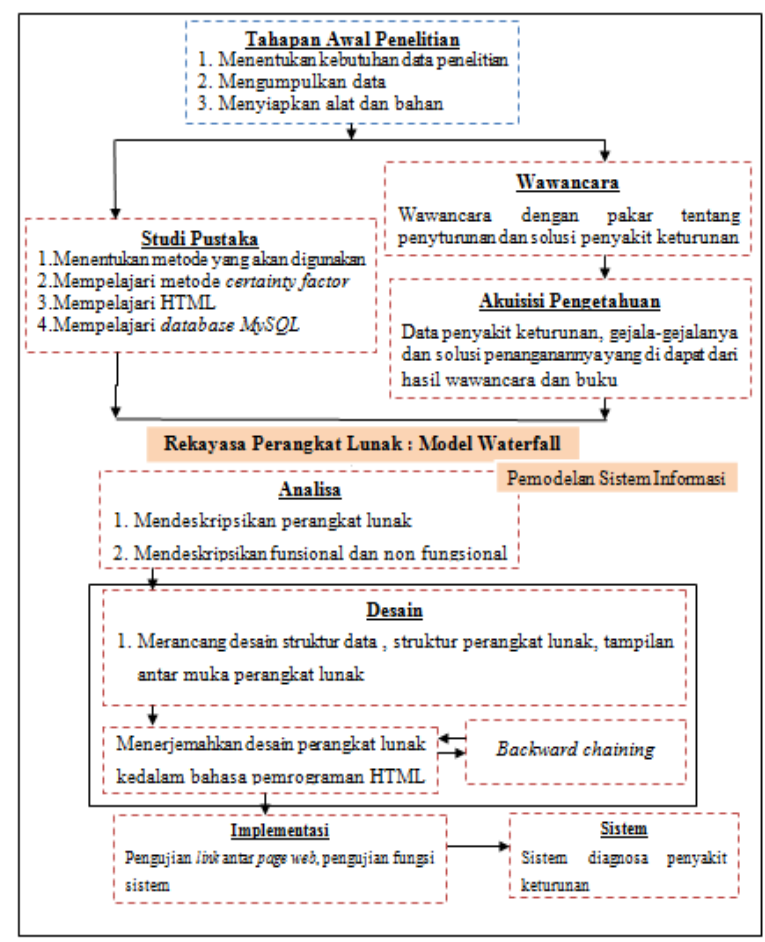

Gambar 1. Metode Penelitian 


\section{Tahap Awal Penelitian}

Penelitian dimulai dengan menentukan kebutuhan data penelitian dengan mencari penyakit keturunan berikut dengan gejala-gejala, kemudian data dikumpulkan dan menyiapkan bahan penelitian.

\section{Pengumpulan Data}

Tahap awal dalam penelitian ini yaitu melakukan pengumpulan data. Mecari dari berbagai sumber baik itu dari buku, internet, jurnal dan pakar untuk mengetahui hal-hal yang diperlukan pada penelitian yaitu penyakit-penyakit pada keturunan, gejala-gejala penyakit tersebut dan solusi untuk menangani.

\section{Wawancara}

Mengadakan tanya jawab langsung dengan seorang pakar penyakit spesialis dalam, sehingga pada penelitian ini data yang di dapat lebih akurat yang tidak terpaku pada studi pustaka.

\section{Akuisisi Pengetahuan}

Setelah tahap wawancara, semua data yang dibutuhkan oleh perangkat lunak dikumpulkan menjadi satu yaitu data penyakit keturunan, gejalagejala dan cara penanganannya.

\section{Rekayasa Perangkat Lunak}

Membangun perangkat lunak menggunakan model waterfall, yang urutannya terdiri dari analisis, desain, kode, tes. Tahap analisis yaitu mendeskripsikan kebutuhan fungsional dan nonfungsional. Tahap desain yaitu merancang struktur data, struktur oerangkat lunak, tampilan antar muka perangkat lunak. Tahap kode dilakukan penerjemahan desain perangkat lunak kedalam bahasa pemrograman HTML, pada tahap ini metodebackward chaining diterjemahkan kedalam kode, selanjutnya tahap testi yaitu melakukan pengujian sistem terhadap koneksi tiap link page, koneksi database.

\section{Sistem}

Pada tahap ini aplikasi telah selesai dan siap untk digunakan.

\section{TINJAUAN PUSTAKA}

\subsection{Sistem Pakar}

Sistem pakar adalah sebuah sistem yang diciptakan berdasarkan dari teori seorang ahli atau lebih, dan kemudian dikonversikan dalam sebuah komputer untuk memudahkan pengguna dalam menggunakan sistem yang ada untuk menyelesaikan masalahmasalah yang dimiliki agar mendapatkan hasil yang akurat. Sistem pakar akan melakukan proses mengenai penyakit keturunan yang diakses berdasarkan gejala yang ada yang kemudian akan menuju dalam tahap diagnosa[1][3].

\subsection{Penyakit Keturunan}

Penyakit keturunan adalah penyakit yang di turunkan turun menurun dari generasi ke generasi berikutnya oleh faktor genetik. Penyakit keturunan memang sudah dimiliki oleh seorang anak sejak lahir atau dalam kandungan, namun sebagian kasus orangtua hanya membawa penyakit kepada anaknya, ini artinya penyakit tersebut sudah ada dalam diri seorang anak, hanya saja penyakit tersebut tidaklah aktif,penyakit akan aktif apabila dipicu oleh lingkungan dan gaya hidup anak tersebut.

\subsection{Backward Chaining}

Backward Chaining adalah salah satu metode yang digunakan dalam bidang ilmu kecerdasan buatan. Backward Chaining adalah kebalikan dari Forward Chaining, dimana sebuah objek, akan dikumpulkan segala macam data/informasi untuk mendapatkan suatu hasil yang meyakinkan mengenai objek tersebut.

\subsection{Certainty Factor}

Certainty Factor adalah metode yang biasanya digunakan untuk memberikan sebuah kebenaran pada sebuah kejadian atau hipotesa dengan perhitungan yang telah ditentukan[2].

\begin{tabular}{|l|c|c|}
\hline No. & Certainty Term & $\begin{array}{l}\text { Certainty } \\
\text { Factor }\end{array}$ \\
\hline 1. & Pasti Tidak & -1.0 \\
\hline 2. & Hampir Tidak Pasti & $-0,8$ \\
\hline 3. & Kemungkinan Besar Tidak & $-0,6$ \\
\hline 4. & Mungkin Tidak & $-0,4$ \\
\hline 5. & Tidak Tahu / Tidak Yakin & $-0,2-0,2$ \\
\hline 6. & Mungkin & 0,4 \\
\hline 7. & Kemungkinan Besar & 0,6 \\
\hline 8. & Hampir Pasti & 0,8 \\
\hline 9. & Pasti & 1,0 \\
\hline
\end{tabular}

\section{HASIL DAN PEMBAHASAN 4.1 GAMBAR UMUM SISTEM}

Gambar umum yang dibangun pada Sistem Pakar Mendeteksi Penyakit Keturunan Berbasis Web dengan Metode Backward Chaining, yaitu :

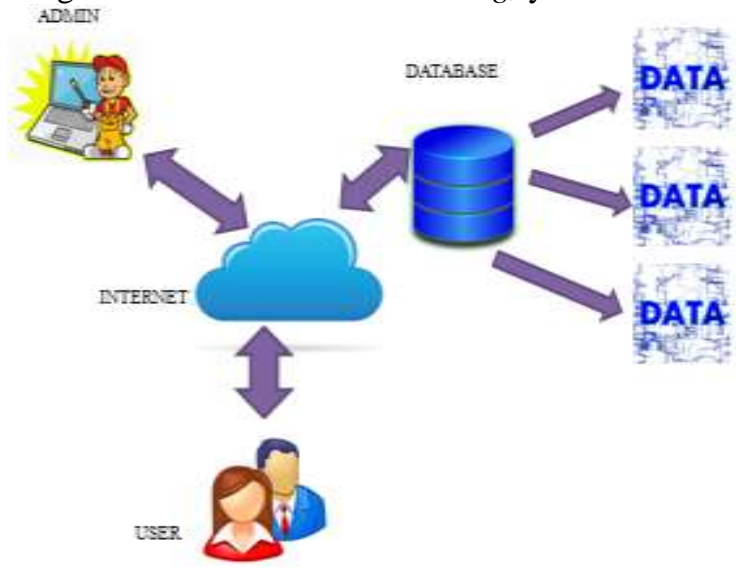

Gambar 2. Blok Diagram Perancangan Sistem 
Jurnal Sistem Informasi dan Ilmu Komputer Prima (JUSIKOM PRIMA)

Vol. 3 No. 1, Agustus 2019

Keterangan :

1. User terdiri dari : user harus terhubung ke sistem agar dapat diakses setelah berhasil terhubung user dapat menggunakan sistem.

2. Database digunakan sebagai menyimpan datadata yang diolah maupun yang sudah diupload ke sistem.

3. Admin digunakan sebagai pengolah data yang ada di sistem.

\subsection{Use Case Diagram}

Berikut ini adalah use case diagram pada sistem yang dapat dilihat pada gambar 3, yaitu :

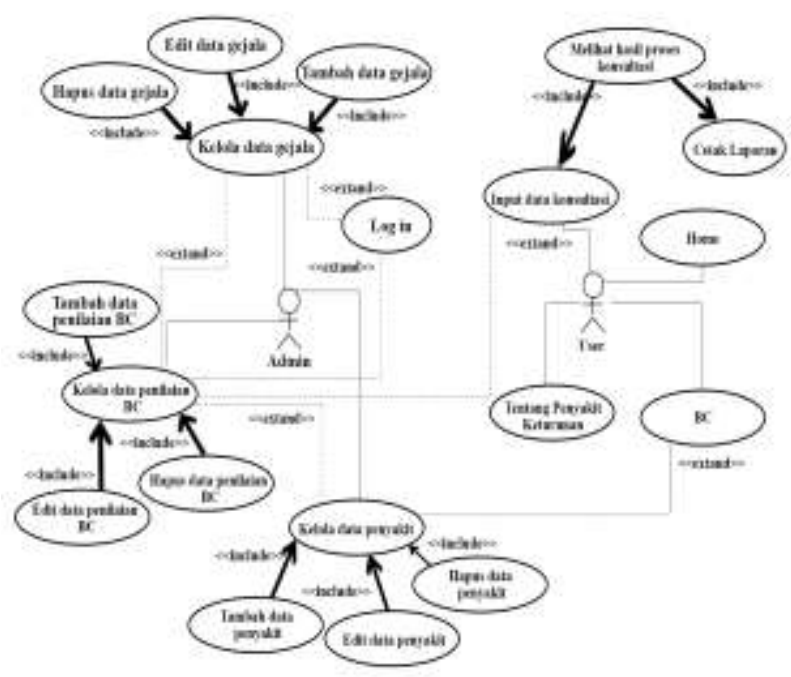

Gambar 3. Use Case Diagram

\subsection{Activity Diagram}

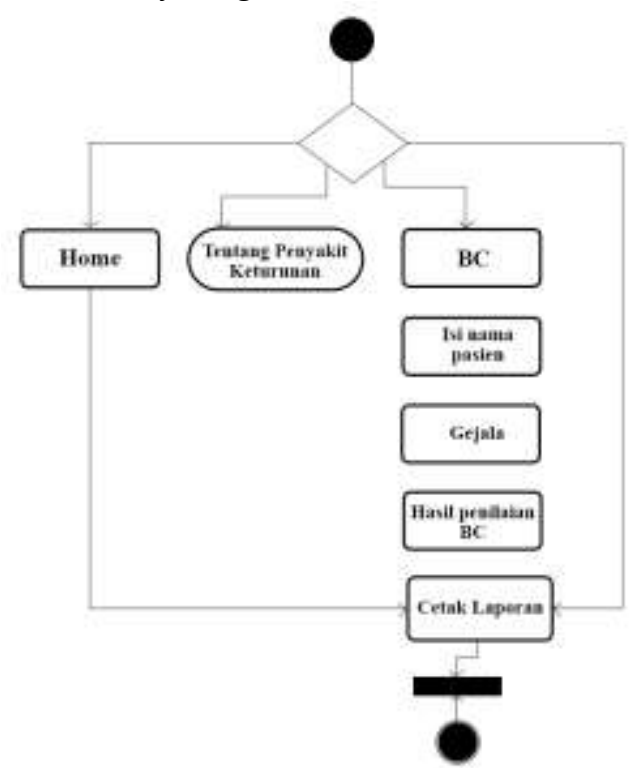

Gambar 4. Activity Diagram

\subsection{Class Diagram}

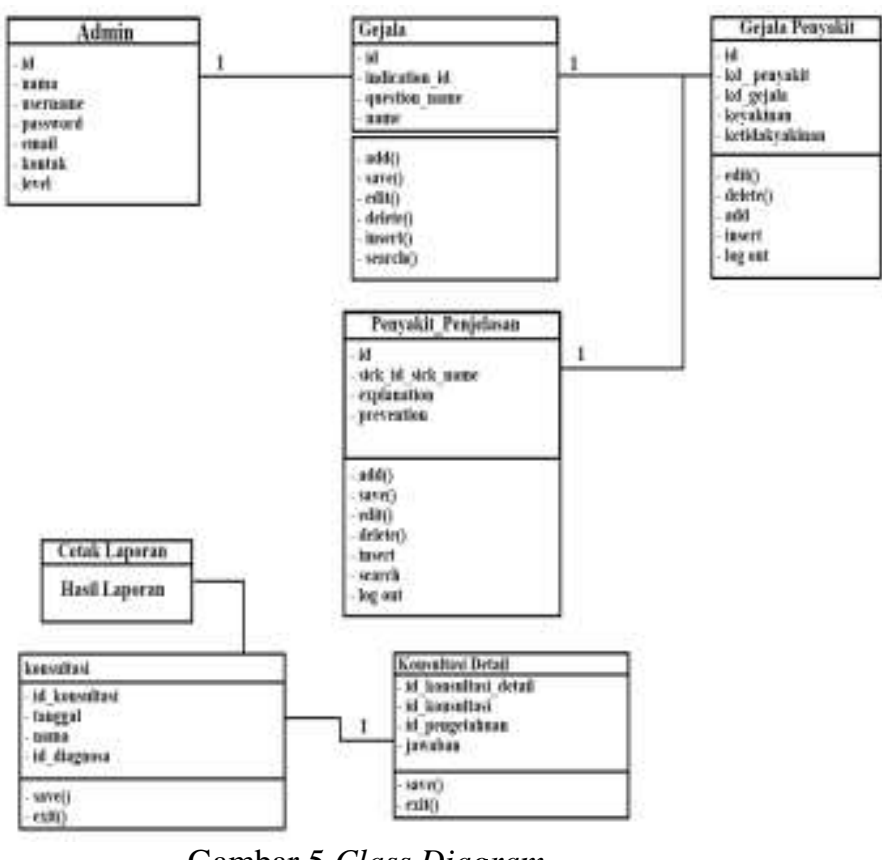

Gambar 5 Class Diagram

\subsection{Form Program}

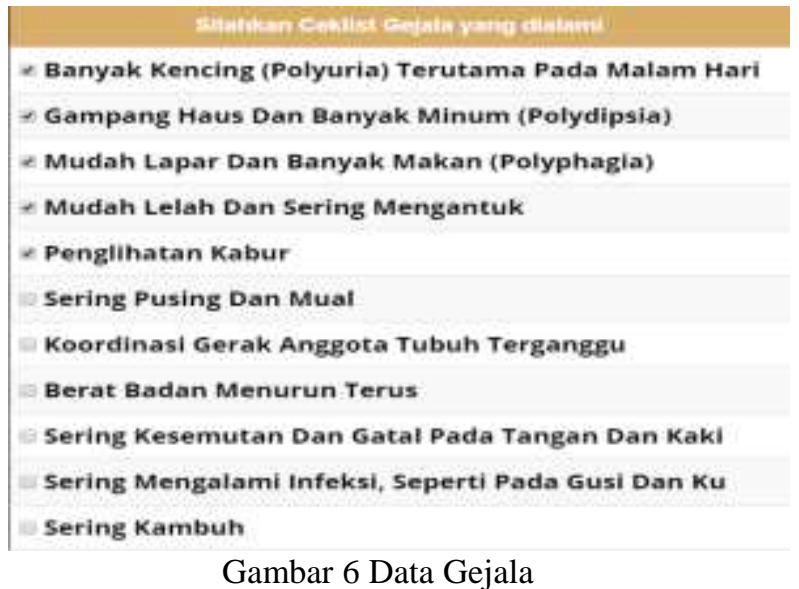

Setelah pengguna melakukan login dengan memasukkan nama pasien, maka pengguna akan melakukan ceklist gejala apa saja yang sudah terjadi terhadap tubuh pasien, setelah ceklist selesai dilakukan, maka klik tombol proses pada bagian bawah. 


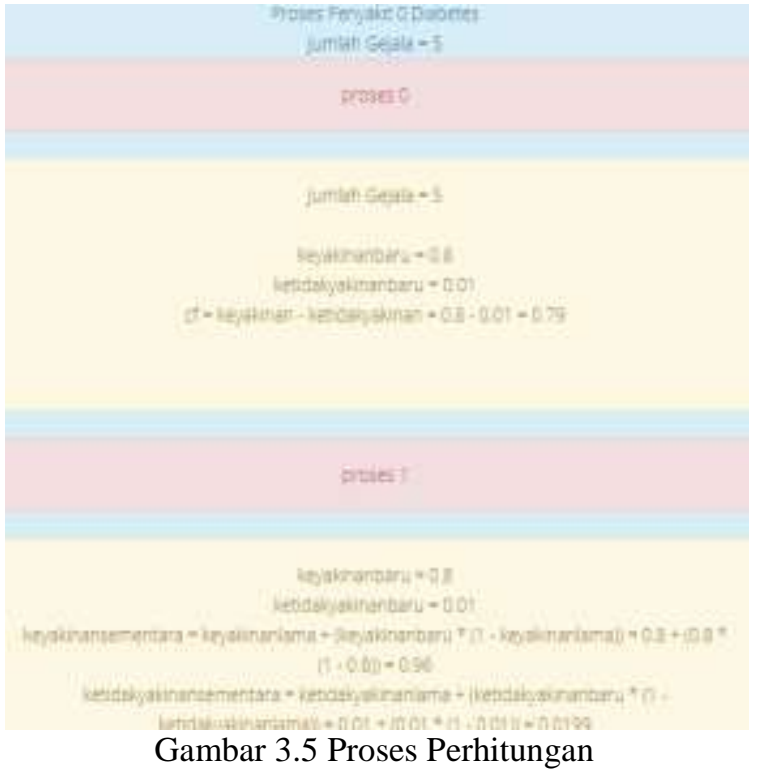

Proses perhitungan pembobotan dihitung berdasarkan perhitungan certainty factor, gejala yang dipilih akan diproses pada semua penyakit yang memiliki gejala yang sama.
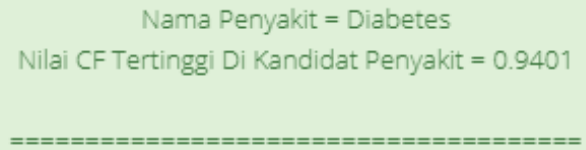

Nama Penyakit $=$ Hipertiroid

Nilai CF Tertinggi Di Kandidat Penyakit $=0.79$

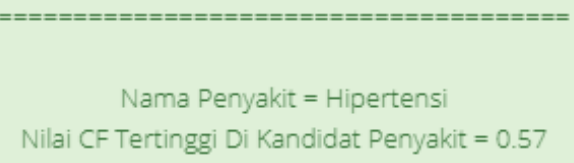

Nilai tertinggi dari perhitungan gejala adalah Diabetes,

dengan nilai $\mathrm{CF}=0.9401$

Tindakan Pencegahan

1. Mengurangi porsi makan

2. Olahraga

3. Menurunkan berat badan

4. Sarapan sangat penting

5. Hindari makanan berlemak

6. Hindari minuman manis

7. Hindari stres

Gambar 3.6 Hasil Perhitungan

Hasil perhitungan dapat dilihat dengan melakukan klik pada menu disamping proses perhitungan, pada hasil perhitungan ini user dapat melihat hasil akhir dari proses perhitungan, nilai tertinggi pada suatu penyakit akan menjadi penentu penaykit apa yang diderita oleh pasien. Pasien juga dapat melihat tindakan pencegahan atau pengobatan yang ada pada bagian bawah hasil nilai tertinggi.

\section{KESIMPULAN}

Ada beberapa kesimpulan yang ada pada penelitian ini, yaitu:

1. Sistem pakar adalah ilmu yang dapat dipakai untuk diagnosa penyakit.

2. Metode Backwrd Chaining yang digunakan dapat menentukan penyakit apa saja yang ada berdasarkan gejala yang sudah dipilih, akan tetapi hasil yang ada menjadi tidak pasti, karena dalam 1 gejala bisa dimiliki oleh lebih dari satu jenis penyakit.

3. Metode Certainty Factor dapat digabung dengan metode Backward Chaining, Certainty Factor dipakai untuk melakukan pembobotan, agar hasil menjadi lebih meyakinkan.

\section{UCAPAN TERIMA KASIH}

Penulis mengucapkan terima kasih kepada Universitas Prima Indonesia Medan, Dosen Pembimbing, orang tua, saudara, dan teman-teman sekalian yang telah medukung dalam penyusunan jurnal ini dan dapat kami selesaikan dengan baik.

\section{DAFTAR PUSTAKA}

[1] Ajar Rohmanu,Cindy Novelia. 2017. Prototipe Sistem Pakar Penyakit Kulit Pada Manusia Dengan Metode Forward Chainning Dan Backward Chainning Berbasis Android. Jurnal ICT Learning.3(1).

[2] Annahl Riadi. 2017. Penerapan Metode Certainty Factor Untuk Sistem Pakar Diagnosa Penyakit Diabetes Melitus Pada RSUD Bumi Panua Kabupaten Pohuwato. Jurnal Ilmiah.9(3).

[3] Ari Hardiansyah Situmorang, Irham Nur Hakim, Muhammad Shofyan. 2016. Aplikasi Sistem Pakar Untuk Mendiagnosa Penyakit Pencernaan Pada Manusia Menggunakan Metode Forward Channing. Jurnal Stmik Amikom Yogyakarta. ISSN : 2302-3805.

[4] Ariyawan ,Made Dwi. 2018. Aplikasi Sistem Pakar Diagnosa Penyakit Umum Pada Manusia Berbasis Web. Jurnal Elektronik Ilmu Komputer Udayana.7(2).

[5] Catur Edi Widodo. 2017. Prototype Sistem Pakar Diagnosis Penyakit Diabetes. Youngster Physics Journal.6(2). 
[6] Cik,Idi Jang, Syaputra , Arizen. 2016. Aplikasi Sistem Pakar Untuk Diagnosa Sakit Gigi Berbasis Web. Jurnal Betrik.7(1).

[7] Feriani A. Tarigan. 2014. Sistem Pakar Untuk Mendiagnosa Penyakit Ginjal Dengan Metode Backward Chaining. Jurnal TIMES.3(2).

[8] Iriani, S. (2015). Penerapan Metode Backward Chaining Pada Sistem Pakar Diagnosa Penyakit Tulang Manusia. IJNS - Indonesian Journal on Networking and Security.4(1).

[9] Kartika, Dewi, Junaidi,Agus. 2018 .Aplikasi Diagnosa Penyakit Lambung Dengan Metode Forward Chaining. Jurnal Teknologi Informatika \& Komputer.4(2).

[10] Samsudin, Usman Selviana. 2017. Aplikasi Sistem Pakar Diagnosa Penyakit Pernapasan Menggunakan Metode Case-Based Reasoning. Jurnal IPTEKS Terapan. ISSN: 1979-9292.

[11] Supina Batubara, Sri Wahyuni, Eko Hariyanto. 2018. Penerapan Metode Certainty Factor Pada Sistem Pakar Diagnosa Penyakit Dalam. Seminar Nasional Royal. ISSN 2622-6510.

[12] Trianto, Joko .2018. Penerapan Metode Forward Chaining Untuk Diagnosa Penyakit Diare Pada Anak Usia 3-5 Tahun Berbasis Mobile Android. Jurnal Informatika Universitas Pamulang,3(2).

[13] Turnip,Mardi. 2015. Sistem Pakar Diagnosa Penyakit THT Menggunakan Metode Backward Chaining. Riau Journal Of Computer Science.1(1).

[14] Yasir, Verdi. 2012. Rekayasa Perangkat Lunak Berorientasi Objek Pemodelan,Arsitektur Dan Perancangan (Modeling, Architectur and Design). Jakarta: Mitra Wacana Media.

[15] Yudhanto,Yudha dan Wijayanto,Andhi. 2017. Mudah Membuat Dan Berbisnis Aplikasi Android Dengan Android Studio. Jakarta : PT.Flex Media Komputindo.

[16] O. Sihombing, E. Indra, S. M. F. Situmeang, and R. E. Suraya, "Penerapan Metode Certainty Factor Pada Aplikasi Sistem Pakar Diagnosa Penyakit Paru Berbasis Web," SNITIK [Prosiding Seminar. Nasional. Inovasi. Teknologi. dan Ilmu Komputer., 2018. 